\title{
AN OBJECTIVE CRITERIA PROPOSAL FOR THE COMPARISON OF MCDM AND WEIGHTING METHODS IN FINANCIAL PERFORMANCE MEASUREMENT: AN APPLICATION IN BORSA ISTANBUL
}

\author{
Mahmut Baydaş $^{1^{*}}$ and Orhan Emre Elma ${ }^{2}$ \\ ${ }^{1}$ Necmettin Erbakan University, Faculty of Applied Sciences, Department of Accounting \\ and Finance Management, Turkey \\ ${ }^{2}$ Necmettin Erbakan University, Faculty of Applied Sciences, Department of Accounting \\ and Finance Management, Turkey
}

Received: 21 May 2021;

Accepted: 30 July 2021;

Available online: 3 September 2021.

\begin{abstract}
Original scientific paper
Abstract: Financial performance research with multi-criteria decision making (MCDM) methods, is a common subject of study not only for researchers in the finance literature, but also in the applied sciences. Financial performance manifests itself in an internal universe that a firm can directly control, while the share return of the same firm is shaped synchronically in an external universe which cannot be controlled directly. On the other hand, preferring the most suitable MCDM and weighting method to use in measuring financial performance is often regarded as a source of uncertainty. In this study, share price is used as an external proxy and a tool for comparing MCDM methods, completely different from the previously proposed approaches based on the superiority of internal features. This study was conducted on 131 manufacturing companies in Borsa Istanbul, covering entire 20-quarter period between 2014 and 2018. The experimental findings of the study provides valid solutions for the MCDM and weighting selection problem, that can be proposed as a practical and indirect solution. The results show that preference ranking organization method for enrichment of evaluations (PROMETHEE) method used with hybrid weighting technique produced by far the best performance rankings in 19 out of 20 quarterly periods when compared to technique for order preference by similarity to ideal solution (TOPSIS) and weighted sum approach (WSA).
\end{abstract}

Key words: Financial Performance, MCDM, Share Return, Spearman's Correlation Coefficient.

* Corresponding author.

E-mail addresses: mbaydas@erbakan.edu.tr (M. Baydaş), oeelma@erbakan.edu.tr (O.E. Elma). 


\section{Introduction}

Performance measurement is vital for companies in order for them to make rational financial decisions at the right time, in the modern competitive markets. The multidimensional, complex and contradictory nature of financial performance, which can be described as the determination of firm success, requires the use of MCDM methods for measurement. MCDM provides simplicity and practicality in performance evaluation by purely converting the performance to a single score with the data consisting of multiple criteria. MCDM approaches summarize many aspects of firm-related behavior, fluctuation and output in a single score. In addition, performance measurement provides comparability with competitor companies, even in the most complex scenarios. Thus, it can be said that MCDM has become a decision support system that can help financial information users in making more straightforward and accurate decisions in financial markets, when they are on the verge of investing.

Literature demonstrates that there are more than 100 MCDM methods to assist decision making processes (Danesh et al., 2017). Despite these benefits, there is still no consensus on choosing the right method, for a specific real-life scenario. When MCDM methods use the common decision matrix consisting of the same data, their goals are essentially similar in terms of choosing the best alternative. In fact, many MCDM types create similar rankings with significant correlation levels (Karaoğlan \& Şahin, 2018). However, different weighting methods based on a fixed MCDM are more likely to create different rankings, whether they are objective or subjective. Since different technical approaches and hypothetical limitations affect the ranking results of the methods, this may affect the whole order, not just the best alternative. This is a chronical and inherent problem in the MCDM paradigm as the optimal order is essentially unknown.

In the uncertainty of the optimal, it can be said that the MCDM models which can picture the goal-oriented actual life scenarios with a sound mathematical background are more useful, practical, acceptable and reliable for decision makers. As a quantitative comparison measure, correlation coefficient between the ranking produced by MCDM methods and an independent proxy representing real life has not discussed comprehensively in the literature. For this purpose, it would be useful to analyze and conceptualize the proposal of this approach, specifically in financial performance studies.

In this study, a comprehensive analysis will be made in order to test the novel approach mentioned. At this research, financial performance will be measured at a constantly developing market on the basis of 7 decision criteria for 131 manufacturing companies registered in Borsa Istanbul (BIST), in 20 quarters between 2014 and 2018. In order to ensure comparability, 3 popular types of MCDM will be used with 3 types of weighting method thoroughly used. The relationship between the obtained MCDM ranking results and the simultaneous share-return rankings will be analyzed with the Spearman correlation test.

In this regard, the aim of the study is to reveal the practicality of Rho correlation coefficient in MCDM methods, which expresses the relationship level of the financial performance of manufacturing firms measured by MCDM methods, with their reallife share returns as an indirect superiority criterion. Based on this criteria, the hypotheses of the study are as follows:

H1: There is a relationship between financial performance measured by MCDM and the share return of the respective firm. 
A Novel and Practical Criteria Proposal for Selecting the Suitable MCDM and Weighting...

H2: In the given period, one MCDM method produces higher Rho coefficient than another MCDM method.

H3: In the given period, one weighting technique produces higher Rho than another technique.

These hypotheses could be regarded as an alternative and indirect solution to the selection problem of MCDM methods and weighting techniques, which have been studied in the literature for many years.

\section{Literature}

In line with the purpose of the study, the literature is divided into three segments at this section. Studies on MCDM and weighting method selection, and research on the measurement of financial performance with MCDM methods and comparing ranking results with share returns were demonstrated, respectively. Finally, although there is little research on the usability of Rho production capacity to classify MCDM methods, the related literature will be examined.

\subsection{MCDM and the Selection of Weighting Methods}

There are many suggestions on which reference criteria should be selected for the MCDM methods that can perfectly fit for the given real life problem. When the approaches for the method selection in the literature are examined, it can be clearly seen that the process of determining the strengths and weaknesses of the MCDM methods to solve a specific problem is vital. It may be efficient to examine which advantages and disadvantages are more common for each method and then explore new methods that can effectively combine strengths while eliminating weaknesses (Velasquez \& Hester, 2013). On the other hand, comparative analyzes of the methods show that none of the MCDM methods are regarded as perfect. Ideally and whenever possible, more than one method should be applied to the same problem in order to provide a more comprehensive result for the decision maker (Mulliner et al., 2016).

In addition, choosing a criterion weighting technique among the alternatives is a problem that frequently arises in the MCDM methods. Obviously, criteria weighting has a crucial role in obtaining accurate results (Olson, 2004). Weighting technique selection, like MCDM selection, is also an important problem. Considering that the weights of criteria can significantly affect the result, it is important to pay particular attention to the objectivity factors of criteria weights in the decision-making process. Subjective weighting methods are computationally convenient and more understandable than objective weighting methods. Because, in objective methods, information is derived from each criterion by adopting a mathematical function to determine the weights without the input of the decision maker (Odu, 2019).

According to a research, the capacity of MCDM to represent real life scenarios become more vital than ever, as these models can now be evaluated more with other measures (Munier, 2006). Therefore, a rational MCDM should not only be based on the internal hypothetical scenario, but also model the actual life explicitly. In other words, a MCDM method which has a significant correlation with proxy actual life rankings can be adopted in method selection, surely if the results are not coincidental. This approach has been examined at previous studies in weighting for different versions of a MCDM type (Yaakob et al., 2016). 


\subsection{Financial Performance and an External Real Time Proxy on the Field of MCDMs}

Measuring financial performance, which should exceed the average human memory and intelligence, with MCDM methods in a complex multi-criteria environment, in order to help financial information users to make critical and more appropriate decisions has gained intensity since the early 2000s. Ertuğrul and Karakaşoğlu (2009) used a wide range of financial ratios to establish the performance ranking of companies in the cement sector registered on Borsa Istanbul. That study proposed a fuzzy TOPSIS-based model with fuzzy AHP in financial performance evaluation. Yalçın et al. (2012) proposed an innovative financial performance rating approach with using AHP-based TOPSIS and VIKOR methods, which relies on accounting based financial performance (AFP) and valuebased financial performance (VFP), in order to generate rankings for the firms in the manufacturing industry sub-sector in Turkey.

Comparing the financial performance ranking results of MCDM with a relevant external ranking, such as share return, is useful for financial information users and can be more helpful in their decisions. Özden et al. (2012) calculated the financial performances of cement industry companies using VIKOR method. Whether there is a relationship between the financial performance rankings and the stock returns of these firms was calculated with the Sperman Rank Correlation coefficient. Öztürk (2017) preferred PROMETHEE method at his study on BIST-50 Index companies in order to generate performance scores. At that research, the relationship between the performance scores for each year and the prices of the stocks were examined. Çalış and Sakarya (2020) investigated the relationship between stock returns and financial performance of banks operating in the BIST Banking Index, with the help of PROMETHEE method. Analysis was performed utilizing the quarterly results of the selected banks in Turkey. Spearman rank correlation test was applied to determine whether there is a statistically significant relationship between stock returns and financial performance.

\subsection{The Usage of Correlation Coefficient between Financial Performance and Share Return as a Benchmark to Compare MCDMs}

After finding significant and strong relationships between financial performance and stock return rankings obtained with MCDM, there are either no known studies or arguably very limited number of research using this method in classifying superiority of the models. However, the Spearman Rho coefficient, which expresses the relationship between financial performance results and share return, can be used to compare different MCDM models and weighting techniques.

A recent comparative study on specific TOPSIS types can be shown as an ambiguous example (Yaakob et al., 2016). The financial performances of Kuala Lumpur stock exchange companies were measured using the TOPSIS method, which is one of the popular MCDM techniques. Along with classical TOPSIS, non-rule based fuzzy TOPSIS approaches were also used. The relationship between the obtained financial performance rankings and current share return rankings was investigated. According to the study, there is a correlation between financial performance rankings of TOPSIS and share return rankings. The study demonstrated the rationale for comparing share return with financial performance in order to compare benchmarking results, validate rankings, prove practicality and effectiveness, and finally showcase the robustness of methods. Based on the power of the correlation 
A Novel and Practical Criteria Proposal for Selecting the Suitable MCDM and Weighting...

coefficient, that study showed a significantly weaker performance compared to other TOPSIS models proposed by classical TOPSIS.

In comparison to the current literature, the distinctive feature of this study is to compare different MCDM methods comperehensively, in terms of data, number of periods and methodological diversity. The usability of Rho will also be evaluated in comparing the performance of MCDMs at this research.

\section{Research Methodology}

In this paper, financial performance measurement is used as a tool to compare MCDM-based approaches. In the empirical study, three popular MCDMs and weighting methods are used to measure the financial performance of manufacturing companies, as seen in Table 1 . In this section, the details of the proposed approach, performance metrics, weighting criteria and MCDM methods are explored.

Table 1. Performance Criteria, Weighting and MCDM Methods Used in This Study

\begin{tabular}{lll}
\hline \multicolumn{1}{c}{ Weighting Methods } & \multicolumn{1}{c}{ MCDM Methods } & \multicolumn{1}{c}{ Criteria } \\
\hline Hybrid & TOPSIS & Altman-Z \\
Entropy & WSA & ROE \& ROA \& ROS \\
Equal Weigthing & PROMETHEE & MVA Margin \& Spread \\
& & MV/BV \\
\hline
\end{tabular}

\subsection{Comparison of MCDM and Weighting Methods for the Evaluation of Companies}

As mentioned in the literature, more than one criterion is required to evaluate the performance of companies. In other words, no single criterion performs best overall. Therefore, a comprehensive procedure is required in order to model firms' performance as a MCDM problem. This study proposes a comparison process for weighting methods using TOPSIS as a control element to compare the results of three weighting methods as shown in Table 1 . The reason for choosing TOPSIS here is that it is a widely recognized and popular MCDM method. In weighting, again widely used entropy weighting and equally weigthing methods were used, as well as hybrid weighting technique as a suggestion.

The same weighting coefficients were used as a control variable to compare the results of the three types of MCDM methods. This study proposes a comparative evaluation process for MCDM methods based on identical weighting. The procedure which is explained in section 3.1 applies here as well. But at this step, different types of MCDMs will be compared. According to the rankings obtained using MCDM methods based on Rho coefficient and share-returns, a method of choosing the most suitable MCDM model will be proposed.

\subsection{Performance Metrics and Preferred Statistical Measure}

At this study seven performance metrics are chosen in order to evaluate financial performance of the manufacturing companies with the help of MCDM, which are Altman-Z score, ROE, ROA, ROS, MVA margin, MVA spread and MV/BV. These 7 criteria are all based on growth and will be explained below. In addition to these, 
Spearman's Rho correlation coefficient is also explained as a non-parametric rank correlation measure.

\subsubsection{Altman-Z Score}

In financial performance practices, this classic criterion is frequently used for evaluating the success, failure or risk of the companies. According to some studies, Altman-Z score growth, which expresses the change in this ratio, is the ratio that best represents shareholder value (Carton, 2004: 281). Altman-Z score is a multidirectional and powerful indicator that can demonstrate success, risk and share return at the same time.Altman-Z score is a utility-based criterion, thus higher values in this ratio are always desired.

\subsubsection{Return on Equity}

Return on equity (ROE) is defined as the ratio of net profit to equity, and it is a classic criterion recommended for evaluating financial performance (Bodie et al., 2003: 456). ROE growth is a utility-based criterion.

\subsubsection{Return on Assets}

Return on assets (ROA) is an indicator which shows the degree of efficiency in the utilization of assets. It is a commonly used measure to evaluate financial performance. ROA growth is also a benefit criterion (Bodie et al., 2003: 457).

\subsubsection{Return on Sales}

Return on sales (ROS) is a classic indicator commonly preferred to evaluate financial performance, which is focusing on how efficient sales are made. ROS growth is a utility-based criterion (Carton, 2004: 110).

\subsubsection{Market Value Added Margin}

Market Value Added (MVA) Margin is the ratio of MVA to sales. MVA is a classic value-based measure for evaluating financial performance. MVA Margin is a relatively new measure derived from the popular market value added ratio. MVA margin growth is also a utility-based criterion (Stewart, 2013: 306).

\subsubsection{Market Value Added Spread}

Market Value Added (MVA) Spread is the ratio of MVA to invested capital. MVA is a classic value-based measure for evaluating financial performance. MVA spread is an old benchmark derived from market value added. MVA spread growth is a utility criterion (Stewart, 2013: 306).

\subsubsection{Market to Book Value Ratio}

It is the ratio of market value to equity. In other words, it is the market value which is created by the book value. According to the literature, MVA spread is an improved version of market to book ratio, and these two ratios essentially serve the same purpose (Stewart, 2013: 118). This ratio is similar to MVA derivatives and in that sense can be regarded as a value-based ratio. 
A Novel and Practical Criteria Proposal for Selecting the Suitable MCDM and Weighting...

Growth rates or rate of change is the equation best described as the change of ratio according to the base period. The financial ratios used in the study and their calculations are listed in Table 2 below.

Table 2. Calculation of the Financial Variables Used in this Study

\begin{tabular}{lll}
\hline \multicolumn{1}{c}{ Ratios } & \multicolumn{1}{c}{ Formulas } & \multicolumn{1}{c}{ References } \\
\hline MVA Spread & $(\mathrm{MV}$ t) - (Inv. Cap. t-1) / Inv. Cap. t-1 & Stewart (2013) \\
MVA Margin & $(\mathrm{MVt}$ - Inv. Cap. t-1) / Sales t-1 & Stewart (2013) \\
Market to Book & Market Value / Equity & Stewart (2013) \\
ROE & Net Income t / Equity t-1 & $\begin{array}{l}\text { Damodaran } \\
\text { (2007) }\end{array}$ \\
& & Bodie et al. (2003) \\
ROA & Net Income / Total Assets & Carton (2004) \\
ROS & Net Income / Net Sales & \\
ALTMAN-Z & 1.2 (Working Capital) + 1.4 (Retained & Carton (2004) \\
& Earnings / Total Assets) + 3.3 (EBIT / & \\
& Total Assets) + 0.6 (Market Value of & \\
& Equity / Total Liabilities) + 1.0 (Sales / & \\
& Total Assets) & \\
Share Return & (Ending Stock Price - Initial Stock & Carton (2004) \\
& Price) / Initial Stock Price & \\
\hline
\end{tabular}

\subsubsection{Spearman's (Rho) Rank Correlation Coefficient}

Spearman's rank correlation is one of the most popular rank correlation coefficient measures (Sałabun \& Urbaniak, 2020). It is denoted by $r_{s}$ and calculated by the following formula:

$$
r_{S}=1-\frac{6 \sum d i^{2}}{n\left(n^{2}-1\right)}
$$

In the formula above, di denotes the difference in paired rankings, and $n$ denotes the number of cases. The Spearman coefficient is interpreted as the percentage of one variable's rank variance explained by the other variable. In this study, conceptualizing the external proxy subject and analyzing it with different data is highly regarded, in order to propose the Rho coefficient as a clear criterion.

Some studies suggest that a positive incremental change in financial performance metrics should provide statistically significant increases for shareholders as a means of adjusted return in the market. Previous work indicated that change scores could be used instead of or in addition to static criteria. (Carton \& Hofer, 2006: 235).

\subsection{MCDM Methods}

In order to avoid using a single method among many MCDM methods and to obtain comparative evaluation results, three popular MCDM methods have been chosen in this study TOPSIS, WSA, and PROMETHEE. TOPSIS was chosen because it is the most widely recognized MCDM method in the utility theory school. PROMETHEE is a widely used and popular MCDM method from the European transitional and pairwise comparison school. WSA, on the other hand, was included in the comparison because it is the simplest method to model daily life. TOPSIS vector normalization differs in ranking production with assumptions of Euclidean distance to ideal values. TOPSIS makes a preference that produces the best global benefit as 
the best alternative. PROMETHEE, on the other hand, differs in ranking production with the preference functions it uses while relying on the advantages of alternatives in pairwise comparison. Finally, in WSA there are no assumptions or limitations other than the normalization.

\subsubsection{Technique for Order Preference by Similarity to Ideal Solution}

Technique for Order Preference by Similarity to Ideal Solution (TOPSIS) was based on the logic of choosing the alternative with the most relative closeness to the ideal alternative. The alternative chosen in this method is at the same time the closest to the ideal solution and the furthest to the nonideal solution. The steps and formulas of the method are as follows (Wang \& Rangaiah, 2017: 561-562):

Step 1. Creating a normalized decision matrix:

$$
F_{i j}=\frac{f_{i j}}{\sqrt{\sum_{i=1}^{m} f_{i j}^{2}}}
$$

Step 2. Obtaining the weighted normalized matrix:

$$
v_{i j}=F_{i j} \times w_{j}
$$

Step 3. Finding positive $\left(\mathrm{A}^{+}\right)$and negative $\left(\mathrm{A}^{-}\right)$ideal solutions:

At first, find the biggest value or in other words the best value of each objective to maximize.

$$
\begin{aligned}
& A^{+}=\left\{\left(\operatorname{Max}_{i}\left(v_{i j}\right) \mid j \in J\right),\left(\operatorname{Min}_{i}\left(v_{i j}\right) \mid j \in J^{\prime}\right) \mid i \in 1,2, \ldots, m\right\} \\
& =\left\{v_{1}^{+}, v_{2}^{+}, v_{3}^{+}, \ldots, v_{j}^{+}, \ldots, v_{n}^{+}\right\}
\end{aligned}
$$

After, find the worst value of each objective, which can be find as the largest and smallest value at the objective matrix for minimization and maximization objective, respectively.

$$
\begin{aligned}
A^{-} & =\left\{\left(\operatorname{Min}_{i}\left(v_{i j}\right) \mid j \in J\right),\left(\operatorname{Max}_{i}\left(v_{i j}\right) \mid j \in J^{\prime}\right) \mid i \in 1,2, \ldots, m\right\} \\
& =\left\{v_{1}^{-}, v_{2}^{-}, v_{3}^{-}, \ldots, v_{j}^{-}, \ldots, v_{n}^{-}\right\}
\end{aligned}
$$

Step 4. Calculating distance values for positive and negative ideals

Distance to positive ideal:

$$
S_{i+}=\sqrt{\sum_{j=1}^{n}\left(v_{i j}-v_{j}^{+}\right)^{2}} \quad i=1,2,3, \ldots, m
$$

Distance to negative ideal:

$$
S_{i-}=\sqrt{\sum_{j=1}^{n}\left(v_{i j}-v_{j}^{-}\right)^{2}} \quad i=1,2,3, \ldots, m
$$

Step 5. Computing relative proximity to ideal solution:

$$
C_{i}=\frac{S_{i-}}{S_{i-}+S_{i+}}
$$

The optimal solution having the largest $C_{i}$ is the recommended solution.

In the decision problem, the most preferred alternatives will be obtained when the values calculated by their proximity to the ideal solutions, which is mentioned in the step above, are placed in a descending order for each alternative.

\subsubsection{Weighted Sum Approach}

Weighted sum approach (WSA) is a method that aims to determine the option that provides the maximum benefit from the set of alternatives. This method is based 
on the calculation of the alternatives' global utilitization value, via taking normalized criterion weights into account. It basically consists of two stages. These are normalization and determination of the total utility (Taşabat et al., 2015). It is the closest and simplest method to the average daily life usage with few subjective limitations. If the units of measure are different, the criteria values are normalized and the total score of each alternative is obtained, after summing up according to the criterion weight.

This method consists of the following two stages (Şen, 2014: 58):

Step 1. Normalization of values:

Normalization step is applied with the practice of the formula below.

$r_{i j}=\frac{y_{i j}-D}{H_{j}-D_{j}}$

Here; $i$ shows the order of the alternative, $j$ designates the order of criterion, $y_{i j}$ refers to the original value of $\mathrm{j}$ criterion for the alternative $\mathrm{i}, H_{j}$ denotes the maximum value of the $\mathrm{j}$ criterion which represents the ideal option, $D_{j}$ signalizes the minimum value of the $\mathrm{j}$ criterion, which represents the ideal option. Accordingly, the maximum utility (Rij) is achieved when it is equal to 1 , concurrently the minimum benefit is achieved when it is 0 .

Step 2. Calculation of the total benefit:

At this stage, the utility value of each alternative is calculated. This is found by multiplying the normalized values with the specified criteria weights. With the notion of $k$ indicating the order of the criteria, the formula is as follows:

$$
u\left(a_{i}\right)=\sum_{j=1}^{k} r_{i j} \cdot v_{j}
$$

After this stage, alternatives can be listed according to their utility values. The most appropriate solution to the decision makers' problem is the alternative with the highest utility value. In cases where cost of the evaluations are made, reverse operations should be performed in normalization and utility value calculations.

\subsubsection{Preference Ranking Organization Method For Enrichment Of Evaluations}

Preference Ranking Organization Method For Enrichment Of Evaluations II (PROMETHEE II) aims to provide a complete ranking of a finite set of viable alternatives, from best to worst. This method is essential for applying other PROMETHEE methods, and most researchers have generally resorted to this version of the PROMETHEE.

The basic principle of PROMETHEE II relies on binary comparison of the alternatives across their recognized criterion. Alternatives are evaluated according to different criteria that need to be maximized or minimized. The application of PROMETHEE II requires two additional types of information. These are criteria weighting and preference function selection, which are left to the user's discretion. For each criterion, the preference function distinguishes the difference between the evaluations obtained by the two alternatives into a degree of preference ranking from zero to one.

Six basic types are recommended in order to facilitate the selection of a particular preference function: (1) general criterion, (2) U-shape criterion, (3) V-shape criterion, (4) level criterion, (5) V-shape and (6) Gaussian criterion. These six types are particularly easy to identify. For each criterion; an indifference threshold (q), value of a strict preference threshold (p), and value of an intermediate value (s) between indifference and strict preference treshold must be fixed. In any case, these parameters have vital significance for the decision maker. PROMETHEE II with the 
first type as the preference function is used in this study. The stepwise procedure for PROMETHEE II is as follows (Behzadian et al., 2010: 199):

Step 1. Determine the deviations according to pair-wise comparisons:

$d_{j}(a, b)=g_{j}(a)-g_{j}(b)$

Here $d_{j}(a, b)$ shows the difference between $a$ and $b$ evaluations for each criterion.

Step 2. Implementation of the preference function:

$P_{j}(a, b)=F_{j}\left[d_{j}(a, b)\right] \quad j=1, \ldots, k$

Here $P_{j}(a, b)$ demonstrates the election of $a$ in respect to $b$ for each criterion, as a function of $d_{j}(a, b)$.

Step 3. Calculation of a preference index:

$\forall a, b \in A, \quad \pi(a, b)=\sum_{j=1}^{k} P_{j}(a, b) w_{j}$

Here, preference indices are determined for each alternative pair. The weighted sum for each criterion is defined as $\pi(a, b)$ and the weight associated with the jth criterion is denoted as $\mathbf{w}_{\mathrm{j}}$.

Step 4. Calculation of transition flows:

$$
\begin{aligned}
& \phi^{+}(a)=\frac{1}{n-1} \sum_{x \in A} \pi(a, x) \\
& \phi^{-}(a)=\frac{1}{n-1} \sum_{x \in A} \pi(x, a)
\end{aligned}
$$

Here $\phi^{+}(a)$ and $\phi^{-}(a)$ indicate the positive outranking flow and negative outranking flow for each alternative, respectively.

Step 5. Calculation of net outranking flow:

$$
\phi(a)=\phi^{+}(a)-\phi^{-}(a)
$$

Here $\phi(a)$ expresses the net outranking flow for each alternative.

The procedure is initiated in order to determine deviations based on binary comparisons. Procedure follows this by using a corresponding preference function for each criterion at step 2, calculating the overall preference index at step 3, and calculating the positive and negative transition flows for each alternative at step 4 . Finally, the procedure ends with the calculation of the net outranking flow for each alternative and the complete ranking.

\subsection{Weighting Methods}

Weighting methods are important in choosing the best alternative and also influencing the ranking. Three weighting methods were chosen in this study. Entropy, which is a popular method among MCDM studies, was chosen as the objective weighting method. Yet again, a common equal weighting and hybrid weighting methods are proposed.

\subsubsection{Equally Weighting Technique (Mean Weight Method)}

It is a technique based on equally weighting of criteria, with the assumption that all criteria used in comparing the performance of alternatives are of equal importance. In order to better observe the importance of criterion weights among MCDM methods, the differences between the results obtained by using other weighting methods can be revealed by regarding the equally weighted criteria as the control group (SSen, 2014: 77). This technique can be used in cases where sufficient knowledge and expert opinion are not available in determining the importance of the criteria. It is one of the widely used and recognized techniques. To better illustrate 
A Novel and Practical Criteria Proposal for Selecting the Suitable MCDM and Weighting...

this technique, in the assumption of 8 criteria, the significance level of each criterion weight is determined as 0.125 , considering the fact that the criteria weights are equal to each other.

\subsubsection{Entropy Weighting Technique}

Many objective weighting techniques have been proposed by researchers in recent years. One of the most popular among them is the Entropy technique. The method is built on the concept of entropy, which is defined by Shannon (1948) as the measure of uncertainty. In information theory, entropy is a criterion for the measure of uncertainty given by the discrete probability distribution. The higher the uncertainty in the data group the higher the entropy value will get. If we have a decision matrix that contains a certain amount of information for alternatives, the entropy method is a tool that can be used to determine the importance ranking of the criteria, in other words the weighting values. It can be said that information value will be higher if the information required in the distribution of decision criteria is less likely, on the contrary information value will be lower if it is highly probable. According to literature, the technique is mathematically formulated as follows (Alp et al., 2015: 69).

Step 1. Normalization of the evaluation index:

$$
r_{i j}=\frac{x_{i j}}{\sum_{j} x_{i j}}
$$

Step 2. Calculation of the measure of entropy for every index:

$$
e_{j}=-k \sum_{j=1}^{n} r_{i j} \ln \left(r_{i j}\right)
$$

Step 3. Defining the measure of weigthing for each criteria:

$$
\mathrm{W}_{\mathrm{ij}}=\frac{1-e_{j}}{\sum_{t=1}^{n}\left(1-e_{j}\right)}
$$

\subsubsection{Hybrid Weighting}

The scoring technique, which is regarded as one of the simplest and basic among subjective criteria weighting techniques, is based on the point allocation approach. In this technique, decision makers are expected to estimate weights based on a previously defined numerical range. The scoring technique begins by assigning an arbitrary score to the most important criterion. To exemplify, a score out of 100 is assigned to the most important criterion, and thereafter lower scores are given to the less important criteria in the ranking, proportionately. This process continues until the least important criterion is scored (Şen, 2014: 78).

The decision makers can prefer equal weighting or subjectively assigning different values to the criteria that make up the problem, based on their own initiatives (Kirkwood, 1997: 59). The decision makers can also give a direct weight value in the subjective weighting. Ultimately, the selection of weights is based on the assumption that the importance of one criterion is more important than another criterion, for the users of the system in question (Gade \& Osuri, 2014: 51).

In hybrid weighting, weights were given by direct scoring for the top two criteria, using the expert opinion. The lower 7 criteria were equally weighted by the weight of the group, as there were not enough expert knowledge on change ratios and MVA margin. For the top two criteria in the hybrid method, weighting is determined for VFP group as $71 \%$ while for AFP group as $29 \%$, based on the average of previous studies in the literature (Yalçın et al., 2012; Alvandi et al., 2013; Esbouei et al., 2014; 
Ghadikolaei et al., 2014; Ünlü et al., 2017). Since the sub-criteria were equally weighted, weighting for each member of the three VFP groups was determined as $23.7 \%$, while for each member of the four AFP groups was designated as $7.3 \%$. Hybrid method was approached as an alternative to equally weighting, because while there is sufficient information about the upper criteria, there is not enough expert knowledge about some sub criteria. In addition, hybrid method is proposed as a partial subjective technique.

\section{Application}

In this section, the application and the results of MCDM-based evaluation method in this study will be presented. First, the data set will be explained briefly, thereafter the experimental process will be expressed, and finally the results and discussion of this research will be discussed.

\subsection{Experimental Design}

In accordance with the aim of this study, 131 manufacturing firms in Turkey was selected as decision alternatives, and seven different ratio values of these companies is selected as decision criterion, in order to measure the financial performance of BIST companies with MCDM methods. The period of the study consists of 20 quarter periods between 2014-2018. The performance metrics for each period was calculated separately. First of all, three different TOPSIS-based weighting methods was used for each period in order to determine the effect of criterion weights. Afterwards, the Rho coefficients for each period was obtained by comparing the MCDM results with the stock return rankings. Weighting models was ranked according to the average Rho coefficient they produce, and the most suitable weighting model was selected. On the other hand, this chosen best weighting method was used as the fixed weight method in the selection of MCDM methods in the next step. According to the results of the MCDM method, the one which produces the highest average Rho coefficient was selected as the most suitable MCDM method. Experimental process is as follows:

Step 1. Preparing a data matrix: FINNET software was used in order to obtain ratios and stock returns, which are regarded as financial performance indicators of firms. The obtained data was integrated into the decision matrix to calculate MCDMs.

Step 2. Weighting calculation: Three different weighting results are obtained by applying equal weighting, entropy and hybrid methods. While quarterly entropy weights produced different results for each quarter, fixed weight values were used in all periods for entropy values and other weighting methods. Equal weighting method was used primarily because sufficient subjective expert opinion on some criteria and change values could not be obtained. In the hybrid method, which is based on point allocation and equal weighting, in order to develop an alternative in comparison, the weight value was directly given to the criteria, as there was sufficient information about the top two main criteria. In the sub-criteria, because sufficient subjective expert opinion on some criteria and change values could not be obtained, equal weighting is preferred. Thus, three different weighting methods were obtained: partial subjective, objective and non-judgmental.

Step 3. Calculation of MCDMs: A total of 60 different MCDM results were obtained for 3 different MCDMs of 131 companies in 20 periods. Adding the TOPSIS results calculated in the weighting, a total of 100 different MCDM calculations were made. In other words, a company's MCDM was calculated 100 times. Just for this reason alone, 
A Novel and Practical Criteria Proposal for Selecting the Suitable MCDM and Weighting...

the research has a comprehensive scope that has not been seen generally in previous MCDM studies. SANNA excel extension was preferred to perform MCDM calculations. This program can analyze very large problems for decision makers in a very short time with various methods (Jablonsky, 2014). For PROMETHEE, the general preference function was used.

Step 4. Evaluation of MCDM ranking results: Periodic stock return rankings that occur simultaneously with MCDM rankings have been subjected to Spearman correlation analysis, in order to better understand and pinpoint MCDMs in terms of producing superior results. This analysis was made in the Minitab software.

Step 5. Use of Rho correlation results as a superiority function in MCDM methods: Both MCDMs and weighting methods are listed according to the 20-period average Rho produced by MCDMs. The method with the best average has been recommended to its decision maker.

\subsection{Findings and Results}

Undoubtedly, the weighting process has a vital place in MCDM theory. It is a classic and popular problem whether subjective or objective methods should be preferred in the weighting phase. These preferences are mostly left to the initiative of the decision maker who can surely involve in the process and consequently settle on a method. However, when decision maker chooses a subjective method, he or she has to seek expert opinion. Thus, the choice of weighting method in the MCDM procedure continues to be a concern for decision makers. In this study, using share price as a proxy of financial performance indicator, weighting method selection becomes more practical and accessible.

Many studies consider end year financial statement data to represent that year. However, these results may also be effected by the cumulative actions of previous years. To bypass this type of unseen outcomes and reach genuine financial values for each year, performance change value can be taken. While the previous literature used static values to be used in the MCDM matrix, this study used the difference between two time periods as a performance indicator. With this method, the performance indicator used can better represent the whole time frame.

This study focused on a comparison over the relative value and result created by MCDM methods, while the previous financial performance literature compared MCDM methods with an evaluation based on capacity and ability. Correlation values created by each MCDM method as regards to the share returns are taken into account as results.

As seen on Table 3, weighting types with a fixed MCDM (TOPSIS) are compared according to the Rho coefficients they produce. According to the results based on the weighting method that yields the best, the hybrid weighting method was suggested by this study. The method suggested in this study, predominantly provided the best significant correlation results. Two outcomes can be derived from these findings: firstly, the probability of obtaining correct results with the right experts is high; secondly the subjective evaluation of the top two criteria is easier and more verifiable than the bottom seven criteria. Sub-criteria may be risky since there are more sub-criteria then main criteria. If decision makers are not confident enough in expert opinion, they can use the Entropy weighting method. According to the findings of this study, long term (20 months) fixed weight value in entropy method is more efficient than short term (3 months) variable weight values. In terms of efficiency, there is an equal weighting method which is positioned almost in the middle of these two weighting methods. Therefore, the following can be said for 
Baydaş \& Elma/Decis. Mak. Appl. Manag. Eng. 4 (2) (2021) 257-279

weighting methods: The efficiency potential and risk of subjective weighting is high. Users can choose the weighting combination that can give the highest Rho with sensitivity analysis. But from there on, they must obtain an order provided they model the results.

Table 3. Rho coefficients of TOPSIS rankings with Share Return rankings according to different weighting types

\begin{tabular}{ccccc}
\hline & $\begin{array}{c}\text { Equal } \\
\text { Weighted }\end{array}$ & $\begin{array}{c}\text { Entropy 3- } \\
\text { Month } \\
\text { Periods }\end{array}$ & $\begin{array}{c}\text { Entropy 20- } \\
\text { Month Period }\end{array}$ & Hybrid \\
\hline Q1 2014 & 0.409 & 0.309 & 0.392 & 0.407 \\
Q2 2014 & 0.501 & 0.545 & 0.591 & 0.757 \\
Q3 2014 & 0.606 & 0.695 & 0.668 & 0.777 \\
Q4 2014 & 0.565 & 0.734 & 0.595 & 0.667 \\
Q1 2015 & 0.50 & 0.458 & 0.48 & 0.609 \\
Q2 2015 & 0.449 & 0.584 & 0.475 & 0.581 \\
Q3 2015 & 0.19 & 0.047 & 0.217 & 0.493 \\
Q4 2015 & 0.485 & 0.18 & 0.52 & 0.594 \\
Q1 2016 & 0.351 & 0.069 & 0.356 & 0.557 \\
Q2 2016 & 0.50 & 0.20 & 0.59 & 0.747 \\
Q3 2016 & 0.632 & 0.714 & 0.699 & 0.777 \\
Q4 2016 & 0.548 & 0.766 & 0.640 & 0.757 \\
Q1 2017 & 0.368 & 0.507 & 0.381 & 0.665 \\
Q2 2017 & 0.554 & 0.531 & 0.591 & 0.779 \\
Q3 2017 & 0.565 & 0.324 & 0.616 & 0.719 \\
Q4 2017 & 0.479 & 0.593 & 0.506 & 0.462 \\
Q1 2018 & 0.436 & 0.478 & 0.469 & 0.635 \\
Q2 2018 & 0.384 & 0.30 & 0.37 & 0.40 \\
Q3 2018 & 0.654 & 0.589 & 0.637 & 0.414 \\
Q4 2018 & 0.562 & 0.269 & 0.572 & 0.611 \\
\hline$p=0$ 000 & & & & \\
\hline
\end{tabular}

Table 4 shows the superiority of hybrid weighting method, whose standard deviation is lower and the Rho production is higher than alternatives. Hybrid method can be recommended to researchers because it has a more efficient and stable structure. In this respect, hybrid method is chosen as the weighing method at this study.

Table 4. Rho coefficients of Weighting Methods with Share Return rankings

\begin{tabular}{lllll}
\hline \multicolumn{1}{c}{ Weighting Method } & Ranking & $\begin{array}{c}\text { Mean } \\
\text { Rho. }\end{array}$ & Pairwise Comparison & St. Dev. \\
\hline Hybrid & 1 & 0.6204 & 14 times best ranking & 0.1075 \\
$\begin{array}{l}\text { Entropy 20-Month } \\
\text { Period }\end{array}$ & 2 & 0.5182 & - & 0.2145
\end{tabular}


A Novel and Practical Criteria Proposal for Selecting the Suitable MCDM and Weighting...

\begin{tabular}{lllll} 
Equally Weighted & 3 & 0.4869 & 2 times second ranking & 0.1220 \\
$\begin{array}{l}\text { Entropy 3-Month } \\
\text { Periods }\end{array}$ & 4 & 0.4460 & 4 times best ranking & 0.1277 \\
\hline$p=0,000$ & & & & \\
\hline
\end{tabular}

Figure 1 indicates the precedence of hybrid weighting method, when it comes to producing significantly higher Rho compared to other methods. The exception is the 3rd quarter of 2018. It is striking that the sector's average return on shares is 0.0136 , when economic volatility is in effect after a relatively long period of stability. Hybrid method showed the poorest performance only in this period.



Figure 1. 3-D Line Chart Graph Showing Rho Coefficient Rankings of TOPSIS with Share Return Rankings According to Weighting Methods.

According to Table 5 below, among the three MCDM methods that are analyzed above, PROMETHEE method can be suggested to decision makers who wants to measure financial performance, as it clearly generates the highest rankings in both Spearman's Rho and Kendall's Tau. 
Baydaş \& Elma/Decis. Mak. Appl. Manag. Eng. 4 (2) (2021) 257-279

Table 5. Spearman's Rho and Kendall's Tau coefficients of different MCDM Rankings with Share Return rankings

\begin{tabular}{|c|c|c|c|c|}
\hline $\begin{array}{l}\text { MCDM } \\
\text { Methods }\end{array}$ & Ranking & $\begin{array}{l}\text { Sprmn } \\
\text { Mean }\end{array}$ & $\begin{array}{l}\text { Sprmn St. } \\
\text { Dev. }\end{array}$ & airwise Comparison \\
\hline PROMETHEE & 1 & 0.7128 & 0.1022 & 19 best ranking \\
\hline TOPSIS & 2 & 0.6320 & 0.1274 & 11 second ranking, 9 third ranking \\
\hline WSA & 3 & 0.5973 & 0.1366 & $\begin{array}{l}1 \text { best ranking, } 8 \text { second ranking, } 10 \\
\text { third ranking }\end{array}$ \\
\hline $\begin{array}{l}\text { MCDM } \\
\text { Methods }\end{array}$ & Ranking & $\begin{array}{l}\text { K. Tau } \\
\text { Mean }\end{array}$ & $\begin{array}{l}\text { K. Tau } \\
\text { St. Dev. }\end{array}$ & Pairwise Comparison \\
\hline PROMETHEE & 1 & 0.5209 & 0.0889 & 19 best ranking \\
\hline TOPSIS & 2 & 0.4583 & 0.1032 & 1 best ranking, 11 second ranking \\
\hline WSA & 3 & 0.4245 & 0.1236 & 12 second ranking, 8 third ranking \\
\hline
\end{tabular}

As seen in the Table 6 below, different MCDM types were compared according to the Rho coefficient they produced, provided that the most efficient hybrid method was used in weighting. According to the findings, the MCDM method that dominantly gives the best results is the PROMETHEE method.

Table 6. Rho coefficients of different MCDM rankings with Share Return rankings

\begin{tabular}{lccc}
\hline & TOPSIS & WSA & PROMETHEE \\
\hline March 2014 & 0.407 & 0.302 & 0.449 \\
June 2014 & 0.757 & 0.672 & 0.808 \\
September 2014 & 0.778 & 0.779 & 0.787 \\
December 2014 & 0.667 & 0.703 & 0.792 \\
March 2015 & 0.609 & 0.473 & 0.681 \\
June 2015 & 0.581 & 0.508 & 0.710 \\
September 2015 & 0.493 & $0.256^{*}$ & 0.654 \\
December 2015 & 0.594 & 0.447 & 0.65 \\
March 2016 & 0.557 & 0.390 & 0.632 \\
June 2016 & 0.747 & 0.749 & 0.777 \\
September 2016 & 0.777 & 0.787 & 0.851 \\
December 2016 & 0.758 & 0.735 & 0.811 \\
March 2017 & 0.665 & 0.579 & 0.668 \\
June 2017 & 0.779 & 0.723 & 0.79 \\
September 2017 & 0.719 & 0.721 & 0.785 \\
December 2017 & 0.462 & 0.512 & 0.665 \\
March 2018 & 0.635 & 0.571 & 0.684 \\
June 2018 & 0.405 & 0.493 & 0.490 \\
September 2018 & 0.414 & 0.609 & 0.629 \\
December 2018 & 0.611 & 0.612 & 0.681 \\
\hline
\end{tabular}

${ }^{*} p=0,003$.

** for the remaining coefficients of the table, $p=0,000$. 
PROMETHEE produced the best results in 19 pairwise comparisons and came second only in one comparison. This method also produces best outcomes in terms of Rho means. It can be said that TOPSIS performs slightly better than WSA in Rho means. In addition, at pairwise comparison, it can be said that WSA is similar to TOPSIS.

Compared to previous studies, these results which cover 20 quarters are not random. The results explicitly show that PROMETHEE produces the best Rho as a MCDM method. The findings of this research can give an idea about the success of PROMETHEE, which is based on binary comparison, does not include traditional normalization, and uses simple preference functions as 0 and 1.

It has been determined that PROMETHEE is a more efficient MCDM model compared to other alternatives in modeling real life scenarios, as shown in Figure 2. The results of this financial performance measurement study are in line with some previous research which states that MCDM methods like PROMETHEE that perform paired comparison in scoring are better and more suitable than others (Kou et al., 2020). This study does not indicate which MCDM model is the best, but simply offers a benchmark that paves the way for it. PROMETHEE is found to be the most suitable MCDM method among 3 alternative MCDMs, in the limitations and conditions of this study.

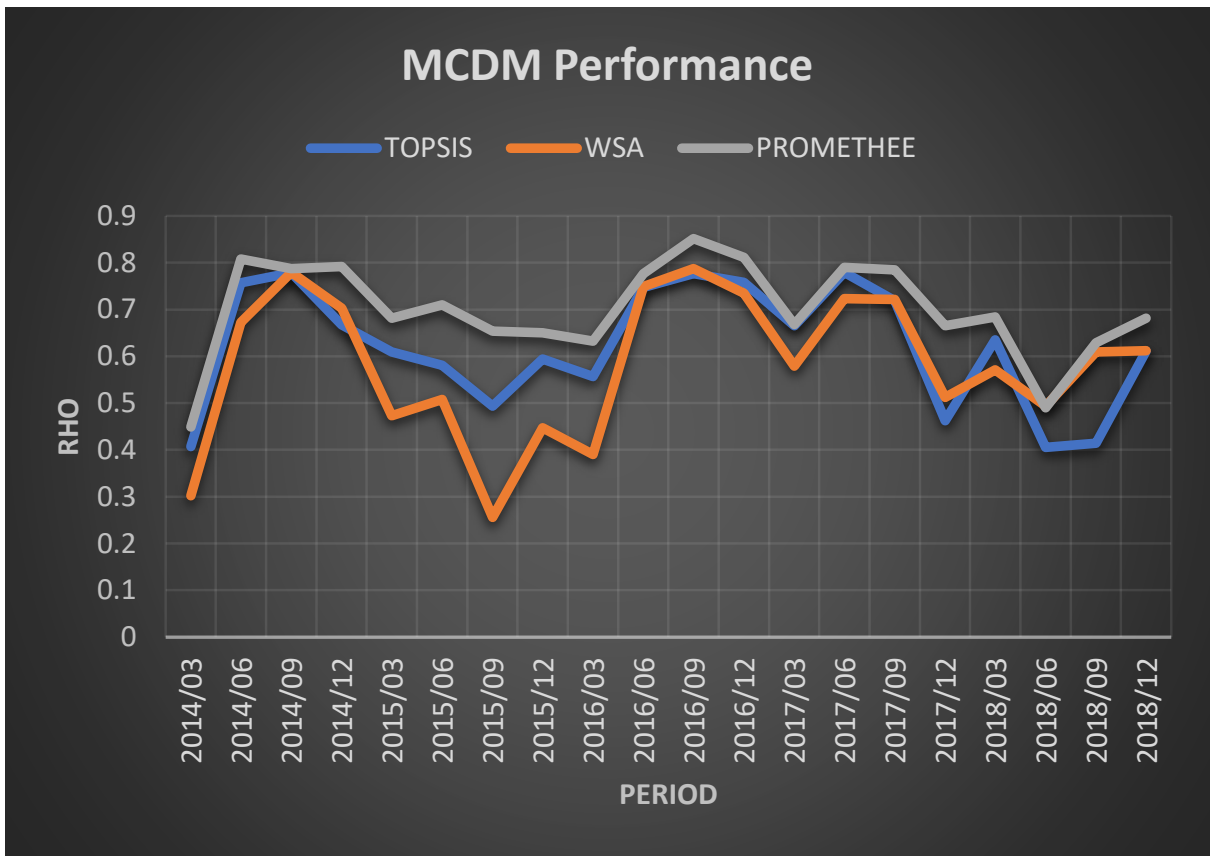

Figure 2. Line Graph showing the Rho coefficient rankings of TOPSIS with Share Return Rankings According to MCDM Methods.

According to Table 7, companies that rank first as regards to the order generated by PROMETHEE are different from other methods, in most cases. TOPSIS and WSA produced generally harmonious first alternatives. The main purpose of MCDM methods is to choose the best alternative. In this case, the ranking produced by PROMETHEE, which shows the best performance in 19 periods, can be accepted as the reference. The only exceptional period is the second quarter of 2018, where WSA is more successful among others. 
Baydaş \& Elma/Decis. Mak. Appl. Manag. Eng. 4 (2) (2021) 257-279

Table 7. Top Performer Companies According to Different MCDMs

\begin{tabular}{lccc}
\hline & TOPSIS & WSA & PROMETHEE \\
\hline March 2014 & GEDZA & GEDZA & KRDMB \\
June 2014 & ULKER & ULKER & KNFRT \\
September 2014 & VESBE & VESBE & EGEEN \\
December 2014 & AFYON & AFYON & JANTS \\
March 2015 & KENT & KENT & KENT \\
June 2015 & AFYON & AFYON & GEREL \\
September 2015 & DOGUB & DOGUB & DOGUB \\
December 2015 & EKIZ & EKIZ & PENGD \\
March 2016 & OTKAR & OTKAR & OYLUM \\
June 2016 & CEMAS & EKIZ & SASA \\
September 2016 & KUTPO & KATMR & KUTPO \\
December 2016 & DOKTA & DOKTA & SNPAM \\
March 2017 & AFYON & KENT & DIRIT \\
June 2017 & ALKA & KAPLM & ALKA \\
September 2017 & YATAS & YATAS & YATAS \\
December 2017 & DOKTA & DOKTA & GEREL \\
March 2018 & DOGUB & DOGUB & CEMAS \\
June 2018 & BSOKE & BFREN & GENTS \\
September 2018 & IZMDC & DOGUB & DMSAS \\
December 2018 & NIBAS & NIBAS & NIBAS \\
\hline
\end{tabular}

MCDM methods may not be compared directly, but with the help of market response these methods can be compared indirectly, which is a proxy solution in financial performance studies. The test results of the hypotheses proposed in this study shows that there is a significant relationship between financial performance and share return, also MCDM methods and weighting methods produced different correlation coefficients. Spearman correlation analysis was conducted to test the first hypothesis which states that there is a significant relationship between financial performance rankings measured by MCDM and share return rankings. According to the analysis, the first hypothesis of the study was accepted $\left(\mathrm{H}_{0}: \mathrm{RhO}=0, \mathrm{H}_{1}: \mathrm{RhO} \neq 0\right)$. In order to test the hypothesis that denotes one MCDM method produces a higher degree of relationship than the other MCDM method in the base period, the correlation coefficients produced by the methods were compared. According to the results, the second hypothesis of the study was accepted $\left(\mathrm{H}_{0}: \mathrm{RhO}=0, \mathrm{H}_{2}: \mathrm{RhO} \neq 0\right)$. In order to test the hypothesis that expresses a weighting method produces a higher degree of relationship than another weighting method in the base period, the correlation coefficients produced by the methods were compared. According to the findings, the third hypothesis of the study was also accepted $\left(\mathrm{H}_{0}: \mathrm{RhO}=0, \mathrm{H}_{3}: \mathrm{RhO} \neq\right.$ $0)$.

The choice of MCDM and weighting methods for the decision maker was a technical problem in itself and considered as a paradox. It can be said that this study suggests a verifiable practical criterion to overcome this problem, in the given setting. In other words, this research shows that it is possible to reduce the cost of 
A Novel and Practical Criteria Proposal for Selecting the Suitable MCDM and Weighting...

not choosing the best alternative in financial decision making with integrating proxy solutions into MCDM methods.

\subsection{Conclusion}

Determining the best alternative in financial performance studies measured by MCDM is a scientific problem. In order to solve this phenomenon, almost a hundred MCDM methods have been derived and proposed to the decision makers in general. Although they have the same purpose, MCDM methods do not always offer the same best alternative and order. The alternative cost of not choosing the best alternative can be very high. In this respect, choosing the most suitable MCDM method becomes a serious concern for the decision maker. Moreover, even if this situation is solved, which weighting method to use is another technical problem in itself.

The relative capacity of the mathematical foundation of the methods is surely important in the reliability of the measurements. In addition, it is also vital to be able to model real life better (Munier, 2006). In this study, the MCDM model which provides a better relationship between financial performance and stock return is assumed the most efficient for decision makers. The results showed that some MCDM models were able to produce explicitly higher Rho coefficients, which leave no room for coincidence. No MCDM model can produce Rho coefficients that are not available. Some MCDM models predominantly provide an existing relationship better than others, and this can imply these methods advantage over others for decision makers, in the given real-life scenarios. The algorithms, assumptions, threshold values, preference functions and normalization methods used by MCDMs may be different. All of these determinants contribute in the difference and significance of the correlation coefficient.

Thus, the market has shown a tendency to approve PROMETHEE clearly and strongly than TOPSIS and WSA. PROMETHEE rankings have a lower standard deviation than other methods, meaning this MCDM method has more consistent and stable characteristic than TOPSIS and WSA, in terms of financial performance measurement. On the other hand, according to the analyzes performed under the same conditions, assuming TOPSIS as a fixed MCDM method, hybrid weigthing technique produced a stronger relationship than entropy and equal weighting methods. As for the weighting methods, hybrid method is more effective than Entropy, which is one of the equal weighting and objective methods. This shows how important the critical touch of expert opinion is. For the Entropy method, unlike previous literature, it can be derived that the accuracy of the results increases when the criteria data for the Entropy method are observed for a longer time period. Based on these results, PROMETHEE method and hybrid weighting technique is proposed as a financial performance measurement tool which is focused on shareholder value.

The superiority of MCDM methods to each other is not absolute and the conditions are important. The number of alternatives, criteria and data types can affect the results. Different conditions can make different types of MCDM methods more successful. MCDM methods dont perform randomly, and some methods are more successful under certain conditions. Therefore, the superiority of MCDM methods over each other are demonstrated distinctively, from a financial decision making perspective.

This research is aiming to contribute to the literature over showcasing certain advantages of different MCDM and weighting methods for financial information users. In order to accomplish that, an objective and practical comparison procedure for the comparison of MCDM methods is proposed. This benchmark is different from 
Baydaş \& Elma/Decis. Mak. Appl. Manag. Eng. 4 (2) (2021) 257-279

most of the previous work in terms of implementing share return as an external proxy. Users of financial information, business owners, company managers, suppliers, investors, shareholders and creditors desire to learn more about the actual performance of the company in order to make an accurate financial decision. Ultimately, it is an important step to find and develop an appropriate benchmark to choose the optimal company for financial information users. Expanding the equivalents of this proxy into the other scientific fields may require detailed research. However, this criterion can be easily recommended for the comparison of MCDM methods for future financial performance measurement studies.

\subsection{Limitations}

This study was made on Borsa Istanbul which is an emerging capital market located in Turkey. The time span of the study is 20 quarterly periods between 20142018 years. Performance measurement system with 7 criteria was applied for 131 companies at Borsa Istanbul Manufacturing Index. The place, time, criteria and number of companies are the limitations of this study. Research results should be evaluated under these constraints.

\subsection{Suggestions for Future Research}

Researchers can use the Rho coefficient proposed in this study to evaluate efficiency in comparing MCDM and weighting methods in future financial performance studies. Also, researchers can explain the reason why some MCDM and weighting methods produce higher Rho coefficients, by concentrating on the mathematical foundation behind them. In addition, it can be investigated why MCDMs that can model complex real life have mathematically more simple background, like binary comparison of PROMETHEE. Finally, if the existence of a real-life proxy sequence associated with MCDM results in quantitative fields such as operations research, engineering and informatics can be confirmed, the approach in this study can be tested on other scientific fields, and thus can be generalized.

Author Contributions: Each author has participated and contributed sufficiently to take public responsibility for appropriate portions of the content.

Funding: This research received no external funding.

Data Availability Statement: The quarterly data of the analyzed companies are taken from the Public Disclosure Platform of Turkey (KAP). The share prices of the firms are provided from Borsa Istanbul Historic and Reference Data Platform.

Conflicts of Interest: The authors declare that they have no known competing financial interests or personal relationships that could have appeared to influence the work reported in this paper.

\section{References}

Alp, İ., Öztel, A., \& Köse, M. S. (2015). Entropi tabanlı Maut Yöntemi ile kurumsal sürdürülebilirlik performansı ölçümü: Bir vaka çalışması. Ekonomik ve Sosyal Araştırmalar Dergisi, 11(2), 65-81.

Alvandi, M., Fazli, S., Gholamreza Kordestani, G., \& Rezaei, R. (2013). Evaluation and ranking the companies of auto and spare parts industry accepted in Tehran Stock 
A Novel and Practical Criteria Proposal for Selecting the Suitable MCDM and Weighting...

Exchange using FAHP and VIKOR. International Research Journal of Applied and Basic Sciences, 5(7), 883-890.

Behzadian, M., Kazemzadeh, R. B., Albadvi, A., \& Aghdasi M. (2010). PROMETHEE: A comprehensive literature review on methodologies and applications. European Journal of Operational Research, 200, 198-215.

Bodie, Z., Kane, A., \& Marcus, J. A. (2003). Essentials of investments. (9th edition). New York: Mc Graw Hill, (Chapter 13).

Carton, R. B. (2004). Measuring organizational performance: an exploratory study. Georgia: Doctoral Dissertation, The University of Georgia.

Carton, R. B., \& Hofer, C. W. (2006). Measuring organizational performance: Metrics for entrepreneurship and strategic management research. Cheltenham: Edward Elgar Publishing Limited, (Chapter 10).

Çalış, N., \& Sakarya, Ş. (2020). Finansal performans ve hisse senedi getirisi ilişkisi: BIST bankacılık endeksi üzerine bir inceleme. Manas Sosyal Araştırmalar Dergisi, 9(2), 1147-1059.

Damodaran, A. (2007). Return on capital (ROC), return on invested capital (ROIC) and return on equity (ROE): Measurement and implications. SSRN: 1105499, Stern School of Business, New York University, 1-69.

Danesh, D., Ryan, M. J., \& Abbasi, A. (2017). A systematic comparison of multi-criteria decision making methods for the improvement of project portfolio management in complex organisations. International Journal of Management and Decision Making, 16(3), 280-320.

Ertuğrul, İ., \& Karakaşoğlu, N. (2009). Performance evaluation of Turkish cement firms with fuzzy analytic hierarchy process and TOPSIS methods. Expert Systems with Applications, 36, 702-715.

Esbouei, S. K., Ghadikolaei, A. S., \& Antucheviciene, J. (2014). Using FANP and fuzzy VIKOR for ranking manufacturing companies based on their financial performance. Economic Computation \& Economic Cybernetics Studies \& Research, 48(3), 141-162.

Gade, P. K., \& Osuri, M. (2014). Evaluation of multi criteria decision making methods for potential use in application security. Karlskrona: Master's Thesis, School of Computing at Blekinge Institute of Technology.

Ghadikolaei, S. A., Khalili Esbouei, S., \& Antucheviciene, J. (2014). Applying fuzzy MCDM for financial performance evaluation of Iranian companies. Technological and Economic Development of Economy, 20(2), 274-291.

Jablonsky, J. (2014). MS Excel based software support tools for decision problems with multiple criteria. Procedia Economics and Finance, 12, 251-258.

Karaoğlan, S., \& Şahin, S. (2018). BIST XKMYA işletmelerinin finansal performanslarının çok kriterli karar verme yöntemleri ile ölçümü ve yöntemlerin karşılaştırılması. Ege Academic Review, 18(1), 63-80.

Kirkwood, C. W. (1997). Strategic decision making: Multiobjective decision analysis with spreadsheets. California: Duxbury Press, (Chapter 4). 
Baydaş \& Elma/Decis. Mak. Appl. Manag. Eng. 4 (2) (2021) 257-279

Kou, G., Yang, P., Peng, Y., Xiao, F., Chen, Y., \& Alsaadi, F. E. (2020). Evaluation of feature selection methods for text classification with small datasets using multiple criteria decision-making methods. Applied Soft Computing, 86(105836), 1-14.

Mulliner, E., Malys, N., \& Maliene, V. (2016). Comparative analysis of MCDM methods for the assessment of sustainable housing affordability. Omega, 59, 146-156.

Munier, N. (2006). Economic growth and sustainable development: Could multicriteria analysis be used to solve this dichotomy?. Environment, Development and Sustainability, 8, 425-443.

Odu, G. O. (2019). Weighting methods for multi-criteria decision making technique. Journal of Applied Sciences and Environmental Management, 23(8), 1449-1457.

Olson, D. L. (2004). Comparison of weights in TOPSIS models. Mathematical and Computer Modelling, 40, 721-727.

Özden, Ü. H., Başar, Ö. D., \& Bağdatll, S. K. (2012). İMKB'de işlem gören çimento sektöründeki şirketlerin finansal performanslarının VIKOR yöntemi ile sıralanması. Ekonometri ve İstatistik Dergisi, 17, 23-44.

Öztürk, E. (2017). Farklı finansal raporlardan elde edilen performans ölçütleri ile cari piyasa değerleri arasındaki ilişkinin belirlenmesi: BIST 50, Mali Çözüm Dergisi 142, 45-63.

Sałabun, W., \& Urbaniak, K. (2020). A new coefficient of rankings similarity in decision-making problems. In: Krzhizhanovskaya V. et al. (Eds.) Computational science - ICCS 2020, (pp. 632-645). Switzerland: Springer.

Shannon, C. E. (1948). A mathematical theory of communication. The Bell System Technical Journal, 27, 379-423, 623-656.

Stewart, B. (2013). Best-Practice EVA: The definitive guide to measuring and maximizing shareholder value, New York: John Wiley \& Sons, Inc., (Chapter 5, Glossary).

Şen, S. (2014). Farklı ağırlıklandırma tekniklerinin denendiği çok kriterli karar verme yöntemleri ile Türkiye'deki Mevduat bankalarının mali performans değerlendirmesi. İstanbul: Master's Thesis, Mimar Sinan Fine Arts University Institute of Natural Sciences.

Taşabat, S. E., Cinemre, N., \& Şen, S. (2015). Farklı Ağırlıklandırma tekniklerinin denendiği çok kriterli karar verme yöntemleri ile Türkiye'deki mevduat bankalarının mali performanslarının değerlendirilmesi. Social Sciences Research Journal, 4(2), 96110.

Ünlü, U., Yalçın, N., \& Yağlı, İ. (2017). Kurumsal yönetim ve firma performansı: TOPSIS yöntemi ile BIST 30 firmaları üzerine bir uygulama. Dokuz Eylül Üniversitesi Sosyal Bilimler Enstitüsü Dergisi, 19(1), 63-81.

Velasquez, M., \& Hester P. T. (2013). An analysis of Multi-Criteria decision making methods. International Journal of Operations Research, 10(2), 56-66.

Wang, Z., \& Rangaiah, G. P. (2017). Application and analysis of methods for selecting an optimal solution from the Pareto-Optimal front obtained by multiobjective optimization. Industrial \& Engineering Chemistry Research, 56, 560-574. 
A Novel and Practical Criteria Proposal for Selecting the Suitable MCDM and Weighting...

Yaakob, A. M., \& Gegov, A. (2016). Interactive TOPSIS based group decision making methodology using Z-Numbers. International Journal of Computational Intelligence Systems, 9(2), 311-324.

Yalçın, N., Bayrakdaroğlu, A., \& Kahraman, C. (2012). Application of fuzzy multicriteria decision making methods for financial performance evaluation of Turkish manufacturing industries. Expert Systems with Applications, 39, 350-364. 